\title{
Prevalence of High Risk Pregnancy: in A Tertiary Care Centre of Sagar Division of M.P.
}

\author{
Ravikant Arjariya ${ }^{1}$ Priyanka Tiwari ${ }^{2}$ \\ ${ }^{1}$ Associate Professor, Department of Physiology, BMC, Sagar, M.P. ${ }^{2}$ Assistant Professor, Department of Obstetrics \\ \& Gynaecology, BMC, Sagar, M.P.
}

\begin{abstract}
Background: High risk pregnancy is broadly defined as one in which mother, fetus or newborn is or will be at increased risk for morbidity or mortality before or after delivery. According to WHO, globally about 830 women die from pregnancy or childbirth-related complications every day. About 20-30\% of all pregnancies belong to high-risk category, which is responsible for $70-80 \%$ of perinatal mortality and morbidity.

Hence, the current study was done to determine the prevalence of high-risk pregnancies and associated high risk factors among antenatal women in a tertiary care centre of central India.
\end{abstract}

Aims \& Objectives: To know the prevalence of high-risk pregnancies and associated high risk factors.

Materials and methods: Ethics approval to conduct the study was obtained from the Institutional Ethics Committee. It is a record-based retrospective longitudinal study done among 3898 antenatal women who have attended/ referred to our tertiary care institute, Bundelkhand Medical College, Sagar, M.P. during February 2020 to May 2020.

High-risk pregnancy was classified based on the guidelines from the Pradhan Mantri Surakshit Matritva Abhiyan.

Results: Among 3898 antenatal case record reviewed. Results of this study show that the prevalence of high-risk pregnancy among study participants was $16.54 \%$.

Most of the pregnant women were in age group of 20-35 years that is $94.72 \%$.

Most of the pregnant women were multigravida $57.20 \%$ by gestation.

Regarding obstetric and neonatal outcomes, majority had normal vaginal delivery (60.6\%). The most common high risk factors were history of previous cesarean section $31.94 \%$, Hypertension in Pregnancy $22.17 \%$ \& Abnormal Presentation were 13.95\%.

Conclusion: The current study found that almost one-sixth (16.54\%) of the pregnant women have highrisk pregnancy. Hence, early detection of high-risk pregnancy needs to be done to improve the maternal, obstetric, and neonatal outcomes.

Keywords: Prevalence, High-risk pregnancy, Cesarean section, Hypertension in Pregnancy.

\section{Corresponding Author:}

\section{Dr. Priyanka Tiwari}

Assistant Professor, Department of Obstetrics \& Gynaecology, BMC, Sagar, M.P.

H.No. 2, Type III, Block ' A' Residential complex, BMC Sagar,M.P. 470001, Mob.- 7898573595

Email. - arjariyaravikant@gmail.com

\section{Introduction}

Pregnancy (gestation) is the physiological process of a developing fetus within the maternal body.

High risk pregnancy is defined as one where pregnancy is complicated by factor or factors that 
adversely affects the outcome- maternal or perinatal or both. ${ }^{1}$ All pregnancies and deliveries are potentially at risk. However, there are certain categories of pregnancies where the mother, the fetus or the neonate is in a state of increased jeopardy.

According to WHO, globally about 830 women die from pregnancy or childbirth-related complications every day. About $20-30 \%$ of all pregnancies belong to high- which is responsible for $70-80 \%$ of perinatal mortality and morbidity. ${ }^{2}$

Women with high-risk pregnancies should receive care from a special team of health care providers to ensure the best possible outcomes.

High risk pregnancy may result because of various conditions which are there either before getting pregnant such as diabetes or high blood pressure, and complications from a previous pregnancy, or conditions during pregnancy or delivery.

In India about $20-30 \%$ pregnancies belong to high risk category, which is responsible for $75 \%$ of perinatal morbidity and mortality. Early detection and effective management of high risk pregnancy can contribute substantially in reduction of maternal and foetal adverse outcomes. Published by : NHP (National Health Portal of India) in Oct 14, 2019. ${ }^{3}$

Pradhan Mantri Surakshit Matriva Abhiyan is an initiative of Ministry of Health and Family Welfare Government of India to identify high risk pregnancies early and follow them so that they can be referred to health care centers with proper facilities so that women with high risk pregnancies may have healthy pregnancies and deliveries without complications.

Identification of high-risk pregnancy, causes, and its complications through quality antenatal care helps in achieving favorable maternal, obstetric, and neonatal outcome. ${ }^{4,5}$. In addition, women identified to be at high risk need to be followed up at regular intervals through routine care by the health workers at health facility and home visits to prevent the development of any maternal or fetal complications.

Apart from follow-up care, appropriate laboratory investigations and referral services also required to improve the outcome of pregnancy. Prognosis of the outcome also depends on the type of high-risk pregnancy among pregnant mothers. ${ }^{6}$ Hence, identification of type of high-risk pregnancy at earliest stage will be useful in directing the appropriate intervention measures for pregnant women.

\section{Material and Methods}

Ethics approval to conduct the study was obtained from the Institutional Ethics Committee.

This is a record-based retrospective longitudinal study conducted among 3898 antenatal women who have attended/ referred our tertiary care hospital during February 2020 to May 2020 in the Department of Obstetrics and Gynaecology, Bundelkhand Medical College and associated hospitals Sagar M.P. which is a tertiary care hospital in the Bundelkhand region of Sagar division of M.P. India, in which a review of all pregnancy data, which occurred over a four months period was done.

The hospital Maternal and Child Health register was used to collect a list of all pregnancy that occurred during the study period. Medical records of all high risk pregnancy were reviewed. Information of all the cases was extracted from the patient's case notes and Maternal and Child Health register records.

The confidentiality of the patient's personal information was protected.

High-risk pregnancy was classified based on the guidelines provided by Pradhan Mantri Surakshit Matritva Abhiyan (PMSMA) for identification of highrisk pregnancy by health-care workers.

The parameters considered for diagnosis of highrisk pregnancy were also defined as per the guidelines provided by PMSMA. Antenatal women with the following conditions were categorized under high-risk pregnancy:

a. Severe anemia with hemoglobin level $<7 \mathrm{~g} / \mathrm{dl}$

b. Hypertensive disorder in pregnancy (blood pressure $>140 / 90 \mathrm{mmHg}$ )

c. Pregnant women positive for HIV/Syphilis

d. Hypothyroidism (thyroid-stimulating hormone 
values - first trimester: $0.1-2.5 \mathrm{mIU} / \mathrm{L}$, second trimester: $0.2-3 \mathrm{mIU} / \mathrm{L}$, and third trimester: $0.3-3 \mathrm{mIU} / \mathrm{L}$ )

e. Gestational diabetes mellitus (glucose challenge test $\geq 140 \mathrm{mg} / \mathrm{dl}$ )

f. Twin pregnancy or multiple pregnancy

g. Previous history of lower segment cesarean section

h. Younger primi (age $<20$ years) or elderly gravida (age $>35$ years)

i. Malpresentation

j. Bad obstetric history (history of congenital malformation, stillbirth, abortion, premature birth, and obstructed labor)

k. Rh incompatibility

1. Low-lying placenta or placenta previa.

m. Patient with History of any current systemic illnesses)/past illness.

Outcome of pregnancy was categorized based on the following domains:

\section{Obstetric outcome}

i. Type of delivery - preterm $(<37$ weeks of pregnancy), term (37-42 weeks of pregnancy), and postterm delivery ( $>42$ weeks of pregnancy)

ii. Mode of delivery - spontaneous vaginal delivery, assisted vaginal delivery, and lower segment cesarean section.

\section{Neonatal outcome:}

i. Birth weight of child - low-birth weight baby (birth weight $<2.5 \mathrm{~kg}$ ), normal baby (birth weight $\geq 2.5$ $\mathrm{kg})$

ii. Status of birth - live birth, stillbirth, and abortion.

The data collected included maternal age, gestation age, referring facility, date of admission, high risk factors etc. Data was captured and analyzed using Microsoft Excel, and Descriptive statistics was used to analyses data. Categorical variables are displayed as percentages.

\section{Results}

Total 3898 antenatal case record reviewed. Results of this study show that the prevalence of high-risk pregnancy among study participants was $16.54 \%$ (n645).

Most of the pregnant women were in age group of $20-35$ years that is $94.72 \%$ and $2.32 \%$ of pregnant women were less than 20 years old, and $2.79 \%$ percent were more than 35 years of age.

And $2.80 \%$ of pregnant women were multigravida by gestation.

Regarding obstetric and neonatal outcomes, majority had normal vaginal delivery $(60.6 \%)$.

The most common high risk factors were history of previous cesarean section 31.94\%, Hypertension in Pregnancy $22.17 \%$ \& Abnormal Presentation were $13.95 \%$.

Table.1 Prevalence of high risk pregnancy $(\%)$

\begin{tabular}{|l|l|l|l|}
\hline S.NO. & PREGNANCY & NUMBER & PERCENTAGE \\
\hline 1 & High Risk Pregnancy & 645 & $16.54 \%$ \\
\hline 2 & Low Risk Pregnancy & 3253 & $83.46 \%$ \\
\hline 3 & Total Pregnancy & 3898 & $100 \%$ \\
\hline
\end{tabular}

The prevalence of high-risk pregnancy among study participants was $16.54 \%$. 
Table.2 Age wise distribution of prevalence of high risk pregnancy

\begin{tabular}{|l|l|l|l|}
\hline S.NO. & AGE IN YEARS & NUMBERS & PERCENTAGE \\
\hline 1 & $<20$ & 15 & $2.32 \%$ \\
\hline 2 & $20-35$ & 611 & $94.72 \%$ \\
\hline 3 & $>35$ & 18 & $2.79 \%$ \\
\hline 4 & Total & 645 & $100 \%$ \\
\hline
\end{tabular}

Most of the high risk pregnant women are in age group of 20-35 years that is $94.72 \%$.

Table.3 Distribution of high risk pregnancy according to the Gravidity

\begin{tabular}{|l|l|l|l|}
\hline S. NO. & GRAVIDITY & NUMBERS & PERCENTAGE \\
\hline 1 & Primigravida & 258 & $40 \%$ \\
\hline 2 & Multigravida & 369 & $57.20 \%$ \\
\hline 3 & Grand multigravida & 18 & $2.80 \%$ \\
\hline 4 & Total & 645 & $100 \%$ \\
\hline
\end{tabular}

Most of the high risk pregnant women were multigravida $57.20 \%$ by gestation.

Table.4 Distribution of high risk pregnancy according to the mode of delivery

\begin{tabular}{|l|l|l|l|}
\hline S.NO. & MODE OF DELIVERY & NUMBERS & PERCENTAGE \\
\hline 1 & Normal Vaginal Delivery & 391 & $60.62 \%$ \\
\hline 2 & Cesarean Delivery & 254 & $39.38 \%$ \\
\hline 3 & Total Delivery & 645 & $100 \%$ \\
\hline
\end{tabular}

Majority had normal vaginal delivery (60.6\%).

Table.5 Distribution of high risk pregnancy according to the high risk factors.

\begin{tabular}{|l|l|l|l|}
\hline S.NO. & TYPE OF RISK FACTOR & NUMBERS & PERCENTAGE \\
\hline 1 & H/O Previous cesarean section & 206 & $31.94 \%$ \\
\hline 2 & Hypertension in pregnancy & 143 & $22.17 \%$ \\
\hline 3 & Abnormal presentation & 90 & $13.95 \%$ \\
\hline 4 & Anemia in present pregnancy & 82 & $12.71 \%$ \\
\hline 5 & Ante partum hemorrhage & 23 & $3.56 \%$ \\
\hline 6 & Grand multipara & 18 & $2.79 \%$ \\
\hline 7 & Twin pregnancy & 14 & $2.17 \%$ \\
\hline 8 & Post term pregnancy & 13 & $2.01 \%$ \\
\hline
\end{tabular}


Cont... Table.5 Distribution of high risk pregnancy according to the high risk factors.

\begin{tabular}{|l|l|l|l|}
\hline 9 & Medical disorders & 8 & $1.21 \%$ \\
\hline 10 & Elderly primi & 6 & $0.93 \%$ \\
\hline 11 & Obstructed labour & 5 & $0.77 \%$ \\
\hline 12 & Ectopic pregnancy & 4 & $0.62 \%$ \\
\hline 13 & Short stature & 4 & $0.62 \%$ \\
\hline 14 & Total & 645 & $100 \%$ \\
\hline
\end{tabular}

The most common high risk factors were history of previous caesarean section $31.94 \%$, Hypertension in Pregnancy $22.17 \%$, Abnormal Presentation were $13.95 \%$, Anemia in present pregnancy $13.95 \%$ and Ante partum hemorrhage $3.56 \%$.

\section{Discussion}

The prevalence of high-risk pregnancy in my study was found to be $16.5 \%$.

A study done in Puducherry, South India by Marie Gilbert Majella, Gokul Sarveswaran et al also reported the prevalence of high-risk pregnancy were $18.3 \%{ }^{7}$

Other studies in India have reported higher proportion of high-risk pregnancy in contrast to current study findings. Studies done in Nagpur, Haryana, Karnataka and Dharwad have reported that almost onethird of antenatal women had high-risk pregnancy when compared to the current study finding of $16.5 \%$. $\frac{8,9,10,11}{1}$

Variable prevalence is contributed to difference in regions, populations, methodologies, and diagnostic criteria, level of health care centre etc.

In the present study $94.72 \%$ were in the age group between 20 to 35 years, followed by $>35$ years $(2.79 \%)$ and least $(2.32 \%)$ were $<20$ years.

In a study by Jaideep KC, Prashant D, et al. $88 \%$ were in the age group between 20 to 29 years, followed by $<19$ years $(7 \%)$ and least $(5 \%)$ were $>30$ years. ${ }^{10}$

A study conducted by Fereshteh Farajnezhad, Faramarz Shaahmadi et al. Show that 4.4 percent of women were less than $18 \mathrm{y} / \mathrm{o}$ and $\% 7.4$ were more than $35 \mathrm{y} / \mathrm{o}$ and the most age abundance was in age group of $18-35 y / 0$ that was 88.2 percent. ${ }^{12}$
Prevalence of high risk pregnancy was higher i.e. $57.20 \%$ in multigravida as compared to primigravida (40\%).

In a study by Jaideep KC, Prashant $\mathrm{D}$, et al. Prevalence of high risk pregnancy was higher i.e. $77 \%$ in multigravida compared to primigravida $(23 \%){ }^{10}$

Another study done in Rohtak, Haryana showed that prevalence of high risk pregnancy was $13.7 \%$ in multigravida. ${ }^{9}$

In my Present study majority had normal vaginal delivery $(60.6 \%)$, and $39.4 \%$ had caesarean delivery.

The most common high risk factors in my study were history of previous caesarean section $31.94 \%$, Hypertension in Pregnancy 22.17\%, Abnormal Presentation were $13.95 \%$, Anemia in present pregnancy $12.71 \%$, Ante partum hemorrhage 3.56\%, Grand multipara $2.79 \%$ and Twin pregnancy $2.17 \%$.

A. Jadho et al (2017) in their study among pregnant mothers of rural area of Nagpur district found that previous caesarean section was the most common risk factor $(14.49 \%)$ followed by malpresentation $(7.94 \%){ }^{8}$

In A study, by Mehta B, Vijay K, et al. showed that in high risk pregnancies the most common risk factors were as follows: History of abortion (27.4\%), followed by height less than $145 \mathrm{~cm}(24.7 \%)$, hypertension in pregnancy (22\%),history of chronic medical disorder, 
parity more than $4(13.7 \%)$, history of preterm birth (11.6\%), history of stillbirth (9.9\%), history of cesarian section $(8.2 \%)$, and history of birth with congenital anomalies $(3.8 \%){ }^{9}$

J.Chaubey et al (2017) in their cross-sectional study in Karnataka found that bad obstetric history (59.8\%) was the common risk factor among the high-risk mothers. ${ }^{10}$

M. Kumar et al (2015) in their study in Dharwad found that most common risk factor seen was height $<$

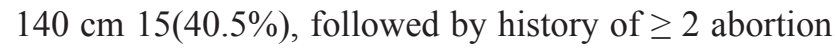
$11(29.7 \%)$ hypertension in pregnancy $4(10.8 \%)$, history of chronic medical disorders $4(10.8 \%)$, Parity $\geq 2(5.4 \%)$, history of pre-term birth 5(13.5\%), history of still birth $3(8.1 \%)$, history of caesarean section $5(13.5 \%) .{ }^{11}$

A study conducted by Fereshteh Farajnezhad, Faramarz Shaahmadi et al. Show that the most risk factor in the scene of previous pregnancies was previous cesarean section $(\% 17.1){ }^{12}$

In a study by Omima A. Muhammeda, Nora A. Khalilb,et al. In the high risk group, the most prevalent risk factors were as follows: History of previous cesarean section (55\%), history of abortion (35.4\%), history of delayed pregnancy (16\%), early pregnancy bleeding less than 20 weeks of gestation (12.5\%), edema (10.4\%), anemia $(9.4 \%),{ }^{13}$

H. Akhtar et al (2009) in their study among the high-risk mothers in Bangladesh found that among the high-risk pregnancies, preeclampsia and PIH were the most common risk factors $(30.97 \%$ each) followed by primigravid $(17.69 \%){ }^{14}$

\section{Conclusion}

In the current study we found that almost onesixth $(16.54 \%)$ of the pregnant women have high-risk pregnancies. History of previous caesarean section $31.94 \%$ and Hypertension in Pregnancy $22.17 \%$ were found to be significantly associated with the prevalence of high risk Pregnancy.

Hence, early detection of high-risk pregnancy needs to be done to improve the maternal, obstetric, and neonatal outcomes.

Pradhan Mantri Surakshit Matriva Abhiyan is an initiative of Ministry of Health and Family Welfare Government of India to identify high risk pregnancies early and follow them so that they can be referred to health care centers with proper facilities so that women with high risk pregnancies may have healthy pregnancies and deliveries without complications. ${ }^{15}$

\section{Ethical Clearance: Yes}

\section{Financial Interest: None}

\section{Conflict of Interest: None}

\section{References}

1. Dutta D C. Special Topics in Obstetrics. D C Datta's Text book of Obstetrics. $8^{\text {th }}$ edi. JAYPEE The health science publisher New Delhi 2015, 716.

2. Mufti S and Mufti S. Identification of High Risk Pregnancy by a Scoring System and its Correlation with Perinatal Outcome. Indian Journal for the Practising Doctor. 2008; 5(1): 1-7.

3. NHP (National Health Portal of India) in Oct 14, 2019.

4. Backett EM, Davis AM, Petroz-Barzavian A. Geneva: World Health Organization; 1984. The Risk Approach in Health Care with Special Reference to Natural and Child Health; World Health Organization Public Health Papers. No. 76; p. 113.

5. Nasah BT, Leke RJ, Doh AS, Moyo JK, Fomulu J, Njikam OM, et al. The risk approach for reducing maternal mortality: The yaounde experience. Int J Gynaecol Obstet. 1991;36:195-201.

6. Singh R, Chauhan R, Nandan D, Singh H, Gupta SC, Bhatnagar M. Morbidity profile of women during pregnancy: A hospital record based study in western UP. Indian J Community Health. 2012;24:342-6.

7. Marie Gilbert Majella, Gokul Sarveswaran, Yuvaraj Krishnamoorthy, K. Sivaranjini, Kalaiselvy Arikrishnan, and S. Ganesh Kumar A longitudinal study on high risk pregnancy and its outcome among antenatal women attending rural primary health centre in Puducherry, South India. J Educ Health Promot. 2019; 8: 12.

8. Jadhao AR, Gawade MD, Ughade SN. Outcome of pregnancy among high risk pregnancies in rural area of Nagpur, Maharashtra, Central India. Int J 
Community Med Public Health. 2017;4:628-33.

9. Mehta B, Vijay K, Amandeep K, Sumit C, Manisha $\mathrm{M}$. Prevalence and correlates of high risk pregnancy in rural Haryana: A community based study. Int $\mathbf{J}$ Basic A Med Sci. 2013;3:212-7.

10. Jaideep KC, Prashant D, Girija A. Prevalence of high risk among pregnant women attending antenatal clinic in rural field practice area of Jawaharlal Nehru medical college, Belgavi, Karnataka, India. Int J Community Med Public Health. 2017;4:1257-9.

11. Kumar MP, Gnanadeep NV, Dixit UR, Patil PS. Prevalence of high risk pregnancy in rural Dharwad. J Dent Med Sci. 2015;14:29-32.

12. Fereshteh Farajnezhad, Faramarz Shaahmadi,
Zahra Fashi, Laila Daaylar Prevalence of high risk pregnancy and some relevant factors in referred women to health centers. Journal Of Scientific Achievements Volume 2, Issue 12, December 2017, Page: 4-7

13. Mohammed A. Omarac, Mona A. Khattab Risky pregnancy among women attending a rural, family healthcare unit. Menoufia Medical Journal, Volume 30 | Number 4 | October-December2017.1093-1097.

14. Akthar H, Sultana S and Siddique A (2009). Neonatal Out Come in High Risk Pregnancy. The Journal of Teachers Association RMC, Rajshahi 22(1) 26-29.

15. Ministry of Health and Family Welfare. Pradhan Mantri Surakshit Matritva Abhiyan. Ministry of Health and Family Welfare. 2016. 